\title{
BMJ open Violence, HIV risk behaviour and depression among female sex workers of eastern Nepal
}

\author{
Reshu Agrawal Sagtani, Sailesh Bhattarai, Baikuntha Raj Adhikari, \\ Dharanidhar Baral, Deepak Kumar Yadav, Paras Kumar Pokharel
}

To cite: Sagtani RA, Bhattarai S, Adhikari BR, et al. Violence, HIV risk behaviour and depression among female sex workers of eastern Nepal. BMJ Open 2013;3:e002763.

doi:10.1136/bmjopen-2013002763

- Prepublication history for this paper is available online. To view these files please visit the journal online (http://dx.doi.org/10.1136/ bmjopen-2013-002763).

Received 21 February 2013 Revised 20 May 2013 Accepted 21 May 2013

This final article is available for use under the terms of the Creative Commons Attribution Non-Commercial 2.0 Licence; see http://bmjopen.bmj.com

School of Public Health and Community Medicine, BP Koirala Institute of Health Sciences, Dharan, Nepal

Correspondence to Dr Reshu Sagtani; rsagtani@hotmail.com

\section{ABSTRACT}

Objectives: The primary objective of the study was to estimate the prevalence of depression among female sex workers (FSWs) of eastern Nepal. The secondary objective was to search for an association between depression, violence and HIV risk behaviour.

Design: Cross-sectional/observational study. Study setting: This study was carried out in five cities of eastern Nepal (Dharan, Itahari, Biratnagar, Damak and Birtamode). Both restaurant-based and street-based FSWs were recruited in the study.

Participants: Women who had been involved in commercial sex activity in the past 6 months and gave informed consent were included in the study.

Primary outcome measure: A score of more than or equal to 16 on the Centre for Epidemiological Studies Depression (CESD) scale was considered as depression.

Methodology: Face-to-face interviews were conducted with respondents who were sought through a snowball sampling technique. Information regarding their depression status, HIV high-risk behaviour and violence was recorded. The estimated sample size was 210.

Results: We interviewed 210 FSWs (both restaurantbased and street-based). The prevalence of depression among respondents was $82.4 \%$. FSWs who had experienced violence were five times more likely to be depressed than those who were not victims of violence. The odds of depression were six times higher among respondents who were involved in any HIV risk behaviour compared with those who were not involved.

Conclusions: The present study reports a high prevalence of depression, HIV risk behaviours and violence among FSWs of eastern Nepal. The mental health of FSWs should also be regarded as an important aspect of HIV prevention efforts which can help to promote the overall health of this population.

\section{INTRODUCTION}

Female sex workers (FSWs) represent a marginalised population that faces many occupational hazards. ${ }^{1}$ They are at higher risk for violence, contracting sexually transmitted

\section{ARTICLE SUMMARY}

Article focus

- What is the prevalence of depression among female sex workers (FSWs) of eastern Nepal?

- Is there any association of depression with violence and HIV risk behaviour which are prevalent in this profession?

Key messages

- Depression is prevalent among the study population, and thus there is a need for future researches in the same direction to cater to the mental health needs of FSWs.

- HIV prevention efforts should also be directed towards mental health issues to promote overall health among this group of vulnerable women.

Strengths and limitations of this study

- This is one of the first attempts to understand the mental health issues of this population in Nepal.

- We used a standardised questionnaire which was translated and adapted according to the local conditions for recording valid data and making comparisons with other studies.

- The external validity of this study is a concern due to the hidden nature of the sampling frame.

- The temporal association of depression with violence and risk behaviour could not be established due to the cross-sectional study design.

- The statistical power of this study is low, which is evident from the width of Cls.

diseases (STDs), including HIV and stigmatisation. ${ }^{12}$ A number of studies have concluded that there are various domains which make sex workers a disadvantaged group and which make prostitution a multidimensional issue. ${ }^{34}$ One of the dimensions is related to the legislative structure of the country in which they operate. In countries like Nepal where commercial sex is illegal, the criminalised status of their work means that commercial sex workers (CSWs) are prone to harassment and violence, are less empowered to negotiate safer sex, and 
are less likely to take legal action against violence and abuse. ${ }^{5}$ Another dimension relates to CSWs not seeking healthcare from public health services mainly because of their negative experiences in these settings such as being 'refused service' and experiencing 'public humiliation by health workers' or the location of public health facilities and the inconvenience of their hours of operation. ${ }^{6-8}$ The poverty-driven phenomenon of 'survival sex' where CSWs accept 'a client who refuses to use a condom' is also an important dimension. ${ }^{9}$

Poor mental health plays a significant role in the involvement of an individual in high-risk behaviours. ${ }^{10}$ More specifically, depressed individuals can be involved in unprotected sex, substance abuse and erratic behaviours. ${ }^{11}$ On the other hand, the fear of contracting HIV/AIDS could be a serious concern among CSWs as the effectiveness of condoms in preventing HIV and sexually transmitted infections has not been proven to be $100 \%$ until now. $^{12}$

Presently, Nepal provides mental health services through 18 outpatient mental health facilities which treat about 300/100 000 general population. This ratio highlights the enormous need for mental health professionals to provide services to the general population. In this scenario, it can be difficult for an individual to be diagnosed and to seek treatment for a mental illness like depression, which is often easily misdiagnosed for a bad or low mood. ${ }^{13}$

Owing to the worldwide concern regarding the spread of HIV/AIDS through this group, most of the time preventive measures are focused on the risks associated with the transmission of HIV/AIDS rather than on the health questions in general or mental health consequences of sex work in particular. ${ }^{14}$ As a result, the mental health needs of this population is generally ignored. The vast majority of research, including biobehavioral surveys in Nepal, addresses physical health and safety and highlights condom use among sex workers, but does not discuss their psychosocial needs and need for counselling services. Thus, this is one of the few studies in Nepal which shows interest in mental health, especially among FSWs.

We designed this study to assess the present depressive status of FSWs and further explore its association with violence and HIV risk behaviour, which are commonly experienced by women in the sex trade. The shortage of health workers, ignorance regarding mental diseases and the stigma attached to prostitution compelled us to go to the workplace of FSWs and enquire about depression. We believe that identifying depression and its associations will help in developing prevention strategies which may reduce HIV risk behaviour, support behaviour change and even improve health outcomes.

\section{MATERIAL AND METHODS}

An observational study was conducted in three districts of eastern Nepal. FSWs who had been involved in commercial sex activity in the past 6 months and who gave informed consent were included. The sample size was derived from a similar study which revealed the prevalence of depression diagnosed through the Centre for Epidemiological Studies Depression (CESD) scale among FSWs to be $70 \% .{ }^{11}$ By using the formula for sample size calculation:

$$
\text { Sample size }(\mathrm{n})=(1.96)^{2} \mathrm{PQ} / \mathrm{L}^{2}
$$

$\mathrm{P}$ is the prevalence of depression from reference study, $\mathrm{Q}$ is the complement of $\mathrm{P}$, ie, $\mathrm{Q}=100-\mathrm{P}, \mathrm{L}$ is precision/ allowable error, which is taken to be $10 \%$ of $\mathrm{P}$ in this study

$$
\begin{aligned}
& =(1.96 \times 1.96 \times 70 \times 30) / 7 \times 7 \\
& =164.64 \ldots 165(\text { approx. })
\end{aligned}
$$

Thus, amplifying by $10 \%$ for possible non-response, the final sample size is $165+16.5=171.5$ or 172 , that is, at least 58 from each district. We planned to interview 210 FSWs, 70 from each district. The sex workers were contacted through snowball sampling; the first few respondents were traced with the help of a non-government organisation-Sahara Nepal-which works for the cause of HIV prevention in the study area. Depressive symptomatology was recorded using the CESD scale, which is a 20-item scale in which a cut-off point of 16 is considered to be appropriate to differentiate respondents with depression ${ }^{15}{ }^{16}$ Questions regarding HIV risk behaviour were adapted from the Family Health InternationalHIV/AIDS/STD Behavioural Surveillance Surveys: for use with FSWs. ${ }^{17}$ A positive history of (1) syringe exchange, (2) sex with an intravenous drug user, (3) sex under the influence of alcohol or drugs, (4) oral sex, (5) anal sex, (6) non-usage of condoms during every sexual encounter and (7) pregnancy after joining the sex trade was considered as being involved in HIV highrisk behaviour. Questions regarding work-related violence were adapted from a questionnaire developed during the WHO multicountry study on women's health and domestic violence against women. ${ }^{18}$ The questions for recording psychological violence were:

A. Has anyone insulted you or made you feel bad about yourself?

B. Has anyone belittled or humiliated you in front of other people?

C. Has anyone done things to scare or intimidate you on purpose?

D. Has anyone threatened to hurt you or someone you care about?

The questions for recording physical violence were:

A. Has anyone pushed or shoved you?

B. Have you ever been physically assaulted (hitting, beating, etc)?

The questions for recording sexual violence were:

A. Have you ever been raped or sexually assaulted?

B. Has anyone attempted to rape or sexually assault you? 
A positive response to any one of the above eight questions was regarded as suffering from violence in the workplace. Women who had suffered from any form of violence and been involved in HIV risk behaviour in the past 6 months at their workplace (street/restaurant) after joining the sex trade were included.

The questions were originally prepared in English and later translated into Nepali for collection of data according to standard translation guidelines. Only completed questionnaires without any missing data were included in the study as it would have been difficult to repeat interviews due to the high mobility of the study population.

Data were analysed using the Statistical Package for Social Sciences (SPSS) V.12.0 (SPSS Inc, Chicago, Illinois, USA). ORs were calculated to assess the association of depression with variables of HIV high-risk behaviour and violence. Significant variables from the bivariate analysis $(p<0.05)$ were then entered into the binary logistic regression model with backward elimination. Ethical approval was taken from the Institutional Ethical Review Board, B P Koirala Institute of Health Sciences (BPKIHS). Informed consent was taken from each respondent. Confidentiality and anonymity were assured and maintained.

\section{RESULTS}

A total of 210 FSWs were interviewed, of which 173 respondents fell in the higher depressive category, making the prevalence of depression among FSWs of eastern Nepal to be $82.4 \%$. FSWs who had been insulted were three times more likely to report depressive symptoms than those who had not (OR 3.28, 95\% CI 1.50 to 7.20 ), as shown in table 1 . The respondents who were humiliated in front of others were twice as likely to be having depression (OR 2.46, 95\% CI 1.06 to 5.70). The risk of depression was about seven times higher among FSWs who gave a positive history of suffering from any form of violence (OR $6.96,95 \%$ CI 3.21 to 15.08 ). Table 2 shows that the distribution of the proportion of individual HIV high-risk behaviours was not largely different for depression. Among the 210 sex workers, no one gave a history of syringe exchange. However, the percentage of women who were involved in at least one mentioned behaviour and depressed was high (85\%). The risk of depression was three times higher in FSWs who had been involved in any one of the mentioned high-risk behaviours (OR 3.20, 95\% CI 1.44 to 7.11 ).

Logistic regression analyses revealed that women who had experienced any form of violence in the last 6 months had a more than five times higher chance of being in the depressive category than respondents who had not (adjusted OR (AOR) 5.89, 95\% CI 2.22 to 15.63), as shown in table 3. Similarly, FSWs who were involved in at least one mentioned HIV risk behaviour were six times more likely to be in a higher depressive category (AOR 6.03, 95\% CI 2.09 to 17.36). Thus, our study shows that violence and HIV risk behaviour are significantly associated with depression.

\section{DISCUSSION}

In our study, the prevalence of depression among FSWs was $82.4 \%$. There are no national data with which we can compare our figure. However, different studies conducted among sex workers reveal fluctuating figures. A study conducted in China revealed that approximately $30 \%$ of the sex workers had elevated depressive symptoms (with a CESD score $\geq 16$ ), $8 \%$ had suicidal ideation, and 9\% had made a suicidal attempt. ${ }^{19}$ An Indian study reported that a majority of the sample $(86 \%)$ had depression for more than 3 days a week and approximately $30 \%$ of the sample reported that they had tried to kill themselves. ${ }^{20}$ These data were comparable with our data, which can also be attributed to the fact that we have open borders and similar sociocultural characteristics. Comparable findings were seen in another study conducted by Alegria et $a l^{10}$ on 127 Puerto Rican sex workers in which $70 \%$ of the sex workers fell into the highly depressive category, which was diagnosed through the same CESD questionnaire. A Nigerian study concluded that in comparison with women of other occupational groups, FSWs were at greater risk of screening positive across many forms of psychopathology. The prevalence ranged from $11.2 \%$ (speech disorder) to $32 \%$ (general psychopathology) among the sex workers, and from $3.2 \%$ (sleep disorder) to $17.6 \%$ (general psychopathology) among the control group. ${ }^{14}$

In accordance with the previous studies, the women who experienced violence were more likely to be depressed compared with those who did not in the current study too. An Indian study concluded that FSWs who experienced higher violence at work and at home had a higher measure of depression. ${ }^{20}$ Harris $e t a l^{21}$ conducted a qualitative study to address the experiences of FSWs in urban Australia. They had been diagnosed with bipolar disorder, and mentally abused by a former partner. Similarly, a study was conducted to examine the association of sexual coercion with HIV-related risk behaviours and suicidal thoughts and attempts among FSWs (FSWs) in Guangxi, China. Multivariate logistic regression analyses indicate that sexual coercion was significantly associated with suicidal thoughts and suicide attempts. ${ }^{22}$

In the current study, FSWs being involved in HIV risk behaviour were six times more likely to be depressed (95\% CI 2.09 to 17.36). Several studies have linked HIV high-risk behaviour with the mental status of a person. A study conducted on 127 Puerto Rican sex workers found that sex workers who had unprotected intercourse with clients were more likely to report high rates of depressive symptoms. Injected drug users were about seven times more likely than those who did not inject drugs to reach high levels of depressive symptoms. ${ }^{10}$ Hutton $e t a l^{11}$ found that depressed patients were more 
Violence, HIV risk behaviour and depression

Table 1 Percentage distribution and OR estimates of work-related violence by depression $(n=210)$

\begin{tabular}{|c|c|c|c|c|c|}
\hline \multirow[b]{2}{*}{ Work-related violence } & \multicolumn{2}{|l|}{ Depression } & \multirow[b]{2}{*}{ OR } & \multirow[b]{2}{*}{$95 \% \mathrm{Cl}$} & \multirow[b]{2}{*}{ Significant values } \\
\hline & Absent (\%) & Present (\%) & & & \\
\hline \multicolumn{6}{|c|}{ Insulted or made to feel bad } \\
\hline Yes & 9.6 & 90.4 & 3.28 & 1.50 to 7.20 & $0.001^{\star}$ \\
\hline No & 17.4 & 72.6 & & & \\
\hline \multicolumn{6}{|c|}{ Humiliated in front of others } \\
\hline Yes & 9.7 & 90.3 & 2.46 & 1.06 to 5.70 & $0.007^{\star}$ \\
\hline No & 23.9 & 76.1 & & & \\
\hline \multicolumn{6}{|l|}{ Intimidated on purpose } \\
\hline Yes & 9.4 & 90.6 & 2.25 & 0.82 to 6.12 & 0.070 \\
\hline No & 20.4 & 79.6 & & & \\
\hline \multicolumn{6}{|c|}{ Threatened to hurt loved ones } \\
\hline Yes & 17.9 & 82.1 & 0.98 & 0.34 to 2.77 & 0.972 \\
\hline No & 17.6 & 82.4 & & & \\
\hline \multicolumn{6}{|l|}{ Pushed or shoved } \\
\hline Yes & 21.4 & 78.6 & 0.75 & 0.28 to 2.01 & 0.570 \\
\hline No & 17.0 & 83.0 & & & \\
\hline \multicolumn{6}{|l|}{ History of physical assault } \\
\hline Yes & 15.2 & 84.8 & 1.23 & 0.44 to 3.44 & 0.685 \\
\hline No & 18.1 & 81.9 & & & \\
\hline \multicolumn{6}{|c|}{ Raped or sexually assaulted } \\
\hline Yes & 20.0 & 80.0 & 0.84 & 0.26 to 2.67 & 0.760 \\
\hline No & 17.4 & 82.6 & & & \\
\hline \multicolumn{6}{|l|}{ Attempt to rape } \\
\hline Yes & 17.6 & 82.4 & 0.99 & 0.43 to 2.28 & 0.995 \\
\hline No & 17.6 & 82.4 & & & \\
\hline \multicolumn{6}{|c|}{ Suffered from any form of violence } \\
\hline Yes & 10.3 & 89.7 & 6.96 & 3.21 to 15.08 & $<0.001^{\star}$ \\
\hline No & 44.4 & 55.6 & & & \\
\hline
\end{tabular}

Table 2 Percentage distribution and OR estimates of HIV high-risk behaviour by depression $(n=210)$

\begin{tabular}{|c|c|c|c|c|c|}
\hline \multirow[b]{2}{*}{ HIV high-risk behaviour } & \multicolumn{2}{|l|}{ Depression } & \multirow[b]{2}{*}{ OR } & \multirow[b]{2}{*}{$95 \% \mathrm{Cl}$} & \multirow[b]{2}{*}{ Significant values } \\
\hline & Absent (\%) & Present (\%) & & & \\
\hline \multicolumn{6}{|c|}{ Sexual intercourse under influence } \\
\hline Yes & 14.6 & 85.4 & 1.48 & 0.71 to 3.06 & 0.439 \\
\hline No & 20.2 & 79.8 & & & \\
\hline \multicolumn{6}{|c|}{ Sex with an intravenous drug user } \\
\hline Yes & 14.3 & 85.7 & 1.31 & 0.36 to 4.72 & 0.673 \\
\hline No & 18.0 & 82.0 & & & \\
\hline \multicolumn{6}{|l|}{ History of anal sex } \\
\hline Yes & 14.8 & 85.2 & 0.12 & 0.05 to 0.31 & 0.060 \\
\hline No & 12.9 & 87.1 & & & \\
\hline \multicolumn{6}{|l|}{ History of oral sex } \\
\hline Yes & 34.8 & 65.2 & 0.34 & 0.13 to 0.88 & 0.923 \\
\hline No & 15.5 & 84.5 & & & \\
\hline \multicolumn{6}{|c|}{ Condom usage during every sexual encounter } \\
\hline Yes & 20.3 & 79.7 & 0.77 & 0.36 to 1.67 & 0.518 \\
\hline No & 16.6 & 83.4 & & & \\
\hline \multicolumn{6}{|c|}{ History of pregnancy after joining the sex trade } \\
\hline Yes & 12.4 & 87.6 & 1.94 & 0.90 to 4.17 & 0.085 \\
\hline No & 21.5 & 78.5 & & & \\
\hline \multicolumn{6}{|c|}{ Presence of any one HIV risk behaviour } \\
\hline Yes & 14.0 & 86.0 & 3.20 & 1.44 to 7.11 & $0.020^{\star}$ \\
\hline No & 34.2 & 65.8 & & & \\
\hline
\end{tabular}


Table 3 Association of violence and HIV risk behaviour with depression-logistic regression

\begin{tabular}{|c|c|c|c|c|}
\hline \multirow[b]{2}{*}{ Significant variables } & \multirow[b]{2}{*}{ Significant values } & \multirow[b]{2}{*}{ Adjusted OR } & \multicolumn{2}{|l|}{$95 \% \mathrm{Cl}$} \\
\hline & & & Lower & Upper \\
\hline Experienced any one form of violence & $<0.001$ & 5.89 & 2.22 & 15.63 \\
\hline Involved in at least one risky behaviour & 0.001 & 6.03 & 2.09 & 17.36 \\
\hline
\end{tabular}

likely than non-depressed patients to have sex for money or drugs, to have had sex with an intravenous drug user, to have sex when 'high' on alcohol or drugs, to have a greater number of lifetime sex partners, and to abuse alcohol or drugs. In a study conducted in Australia, logistic regression analyses showed that a history of injecting drug use, an early age at the time of leaving home and wanting to leave the sex industry were independent predictors of poor mental health. Distressed sex workers reported fewer sexual health examinations and less consistent condom use with their clients than those who were not distressed. ${ }^{21}$

Our study concludes that there is a high prevalence of depression among FSWs of eastern Nepal. It also infers a significant association of HIV risk behaviour and violence with depression.

There are several limitations of the current crosssectional study. To start with, owing to the cross-sectional study design, the temporal association cannot be proved. We can neither say that depression caused violence and HIV risk behaviour nor that the presence of violence and indulgence in risky behaviour made FSWs depressed. However, this study has provided us a good basis to initiate future longitudinal studies to address the present concern of temporality. ORs suggest that women who suffered from psychological violence were more likely to be depressed, but the percentage distribution shows that the proportion of women who did not suffer from psychological violence also had high depressive scores. Similarly, women who were not involved in the individual HIV risk factor also showed high depressive scores. This disables us from knowing how much of the variance in depression is caused by these variables. The information regarding the frequency and severity of violence and risk behaviour was not recorded, which is also an important limitation of the current study. Although we tried to include FSWs of major cities of eastern Nepal where prostitution is rampant, the hidden group, women working during the last few months or mobile FSWs, might have been missed. The lack of a detailed history on substance abuse (possible confounder of depression) is another limitation of the study. The external validity of the study is questionable due to the hidden nature of the sampling frame.

In conclusion, we need to design our HIV prevention strategies in such a way that they address the mental health issues prevalent in this profession. The various agencies working with FSWs can start psychosocial counselling services, spread knowledge regarding mental health importance and highlight the taboos associated with it. Psychiatric evaluation of FSWs can be coupled with their routine blood tests and clinical examinations at voluntary counselling and testing centres. FSWs are scared of the law and thus are less hesitant to practice their right to say ' $\mathrm{NO}$ ' to their clients. We need to help them realise that their clients are also equally answerable to the law and nobody can make them do anything without their consent. Most importantly, there is a need on the part of policymakers to acknowledge the presence of an ever-growing sex industry in Nepal and they should implement ways to address the issues of this population.

Acknowledgements We would like to express our gratitude to the respondents who gave us their valuable time for completion of this study. We are also grateful to the team of NGO-Sahara Nepal who helped us locate the respondents and thus facilitated data collection.

Ethics approval Institutional Ethical Review Board (IERB).

Contributors RS was involved in the conception and design of the study, along with data collection and writing of the drafts. SB was involved in concept refining, developing the questionnaire, writing the drafts and critiquing them. BA helped in translation of the questionnaire, diagnosis of depression and inputs in writing drafts. DB was instrumental in designing the study, and contributed to the statistical analysis and drafting of the results. DKV was involved in a critical analysis of the earlier drafts. PKP was responsible for concept refinement and a critical analysis of the earlier drafts. All the authors have read and approved the final version of the manuscript for scientific publication.

Funding This research received no specific grant from any funding agency in the public, commercial or not-for-profit sectors.

Competing interests None.

Provenance and peer review Not commissioned; externally peer reviewed.

Data sharing statement No additional data are available.

\section{REFERENCES}

1. Popoola BI. Occupational hazards and coping strategies of sex workers in south western Nigeria. Health Care Women Int 2013;34:139-49.

2. Vanwesenbeeck I. Another decade of social scientific work on sex work: a review of research 1990-2000. Annu Rev Sex Res 2001;12:242-89.

3. Harcourt C, Van Beek I, Heslop J, et al. The health and welfare needs of female and transgender street sex workers in New south Wales. Aust N Z J Public Health 2001;25:84-9.

4. Minichiello V, Marino R, Browne J, et al. Male sex workers in three Australian cities: socio-demographic and sex work characteristics. $J$ Homosex 2001;42:29-51.

5. Arnott J. Sex workers and law reform in South Africa. HIV AIDS Policy Law Rev 2004;9:78-80.

6. Stadler J, Delaney S. The 'healthy brothel': the context of clinical services for sex workers in Hillbrow, South Africa. Cult Health Sex 2006;8:451-63.

7. Muyinda $H$, Seeley J, Pickering $H$, et al. Social aspects of AIDS-related stigma in rural Uganda. Health Place 1997;3:143-7. 
8. Kippax S, Crawford J. Dirty and diseased and undeserving: the positioning of HIV positive women. Soc Sci Med 1996;43:1371-7.

9. Collins J, Rau B. AIDS in the context of development. UNRISD Programme on Social Policy and Development, Paper No. 4, UNRISD and UNAIDS 2000.

10. Alegria $\mathrm{M}$, Vera $\mathrm{M}$, Freeman $\mathrm{DH}$, et al. HIV infection, risk behaviors and depressive symptoms among Puerto Rican sex workers. Am J Public Health 1994;84:2000-2.

11. Hutton HE, Lyketsos CG, Zenilman JM, et al. Depression and HIV risk behaviors among patients in a sexually transmitted disease clinic. Am J Psychiatry 2004;161:912-14.

12. Holmes KK, Levine R, Weaver M. Effectiveness of condoms in preventing sexually transmitted infections. Bull World Health Organ 2004;82:454.

13. Report submitted by South East Asian Office (WHO) on Conquering Depression: You can get out of the blues. 2011.

14. Akinnawo EO. Mental health implications of the commercial sex industry in Nigeria. Health Transition Rev 1995;5: 173-7.

15. Myers JK, Weissman MM. Use of a self-report symptom scale to detect depression in a community sample. Am J Psychiatry 1980;137:1081-84.
16. Roberts RE, Vernon SW. The Center for Epidemiologic Studies Depression Scale: its use in a community sample. Am J Psychiatry 1983;140:41-6.

17. Family Health International. Behavioral surveillance surveysguidelines for repeated surveys in population at risk of HIV. Arlington, USA: Family health International, 2000.

18. World Health Organization. WHO multi-country study on women's health and domestic violence against women: summary report of initial results on prevalence, health outcomes and women's responses. Geneva, Switzerland: World Health Organization, 2005

19. Yan Hong Y, Fang X, Li X, et al. Self-perceived stigma, depressive symptoms, and suicidal behaviors among FSWs in China. J Transcult Nurs 2010;21:29.

20. Suresh G, Furr LA, Srikrishnan AK. An assessment of the mental health of street-based sex workers in Chennai, India. J Contemp Crim Justice 2009;25:186.

21. Harris M, Nilan P, Kirby E. Risk and risk management for Australian sex workers. Qual Health Res 2011;21:386-98.

22. Wang B, Li X, Stanton B, et al. Sexual coercion, HIV-related risk, and mental health among FSWs in China. Health Care Women Int 2007:28:745-62. 